\title{
Metilfenidato: influência da notificação de receita A (cor amarela) sobre a prática de prescrição por médicos brasileiros
}

\author{
Elisaldo A. Carlini ${ }^{1}$ \\ Solange A. Nappo ${ }^{1}$ \\ Vagner Nogueira ${ }^{2}$ \\ Fernando G. M. Naylor ${ }^{2}$
}

Recebido: 28/10/2002 Aceito: 6/1/2003

\section{RESUMO}

Oitocentos e noventa e dois médicos, entre eles neurologistas (463) e psiquiatras (411), responderam a um questionário sobre a prescrição do metilfenidato para o transtorno do déficit de atenção e hiperatividade (TDAH).

A maioria dos médicos relatou a ocorrência esporádica de reações adversas não-sérias, tais como dor de cabeça, emagrecimento, inapetência, hiperexcitabilidade, taquicardia, etc; apenas seis médicos, entretanto, relataram casos que poderiam levar à suspeita de dependência, embora nenhum deles satisfizesse os critérios da CID-10 para tal.

A grande maioria opinou que a exigência da notificação de receita A (amarela) é inadequada, criando preconceitos em relação à condição dos pacientes e amedrontando seus parentes. Relatam ainda que tal classificação dificulta a prescrição do medicamento, fazendo muitas vezes com que o metilfenidato se torne a segunda opção para o tratamento de TDAH, além de tornar o produto pouco disponível nas farmácias e dificultar o trabalho dos profissionais. Isso faz com que a adesão ao tratamento se torne mais difícil, pois, além dos vários entraves burocráticos para se adquirir o medicamento, há também o medo por parte dos familiares e do próprio paciente de estar tomando tal medicação.

Neurologistas e psiquiatras argumentam que o controle do metilfenidato deve existir, mas, em se tratando de um medicamento prescrito por especialistas e de não possuir grande potencial de dependência, o receituário azul já seria suficiente para o controle adequado. A classificação do metilfenidato, juntamente com as anfetaminas e com o princípio ativo da maconha (dronabinol), é uma outra questão levantada, sendo tal fato para grande parte dos profissionais uma total incoerência.

Unitermos: Metilfenidato; Prescrições; Medicamentos controlados; Transtorno do déficit de atenção e hiperatividade.

\section{ABSTRACT}

Four hundred and sixty three brazilian neurologists and 411 brazilian psychiatrists answered a questionnaire aimed at to obtain information on the prescription of methylphenidate for the treatment of the Attention Deficit and Hyperactivity Disorder.

The majority of the doctors reported the erratic occurrence of a few non serious adverse reactions such as headache, weight loss, inapetence, hyperexcitability and tachycardia. On the other hand, only six doctors reported cases that cold raise a suspicion of drug dependence, although none of these six cases satisfied the ICD-10 criteria for dependence. The vast majority of the medical doctors manifested the opinion that the especial prescriptions the "Notifications A" of yellow color, the same used for opiates also, as demanded by the Brazilian Health Authorities, is inadequate as it raises misconceptions in relation to the real patient disease and frightens the parents and relatives. The doctors also claimed the such especial prescription form encumbers the prescription of the medicament making methylphenidate the second choice for the treatment and, for this reason, less available in pharmacies and drugstores. As a consequence the adherence to the treatment is more difficult to attain.

The neurologists and psychiatrists agree that a certain control over methylphenidate is necessary, but as it is prescribed mostly by specialists and does not possess an evident abuse potential, the "Prescription Notification B", of blue color, would be enough for efficient control. In fact, according to the doctors, the scheduling in Brazil of methylphenidate in the same list as the amphetamines and dronabinol (the active principle of Cannabis sativa) should be reviewed.

Keywords: Methylphenidate; Prescriptions; Controlled drugs; Attention deficit hyperactivity disorder; Drug dependence.

CEBRID (Centro Brasileiro de Informações sobre Drogas Psicotrópicas) Departamento de Psicobiologia - UNIFESP-EPM.

Novartis Biociências, São Paulo, Brasil. 


\section{Introdução}

O metilfenidato é uma substância que está classificada na Convenção da ONU sobre Drogas Psicotrópicas - 1971 (revisada em 27 de novembro de 1999) - entre as substâncias da lista II. Deve-se salientar que não consta entre essas substâncias nenhuma que pertença ao grupo de opiáceos/opióides.

Por outro lado, de acordo com a Portaria SVS/ MS no 344, de 12/5/98, e RDC no 22, de 15/2/2001, o metilfenidato foi colocado na lista A3 (substâncias psicotrópicas), mas sujeito à notificação de receita $\mathrm{A}$. Nessa lista estão contidas substâncias como metanfetamina ("ice"), fenciclidina ("pó de anjo") e dronabinol (princípio alucinógeno da maconha).

No Brasil, entretanto, também as drogas opiáceas/ opióides (ou narcóticas) que estão listadas em outra Convenção da ONU, a Convenção Única sobre Drogas Narcóticas - 1961, devem ser prescritas com a mesma notificação de receita A. Ou seja, tanto o metilfenidato como os potentes analgésicos e os fortes indutores de dependência, como morfina, meperidina $\left(\right.$ Demerol $^{\circledR}$ ou Dolantina ${ }^{\circledR}$ ), fentanila, etc. são prescritos na mesma notificação A, de cor amarela.

Finalmente, há que se considerar a dificuldade a que os médicos ficam expostos pela grande burocracia imposta para obterem os blocos de notificação A na Vigilância Sanitária.

Diante do exposto, é justificada uma investigação procurando verificar qual é a incidência de dependência induzida pelo metilfenidato em crianças brasileiras que necessitam utilizar o medicamento por indicação e prescrição médica. Paralelamente, o presente trabalho procurará também obter dados sobre outras eventuais reações adversas produzidas pelo metilfenidato. Procurou-se ainda captar a opinião dos médicos sobre a colocação do metilfenidato na lista A3 e as conseqüências advindas desse fato.

\section{Material e métodos}

Um questionário foi elaborado pelo CEBRID, ouvindo alguns médicos neurologistas e psiquiatras. $\mathrm{O}$ anexo 1 mostra o questionário completo, que consta de quatro partes, com um total de 9 perguntas. A primeira parte contém dados de identificação do médico; a segunda parte traz perguntas de 1 a 3 e indaga sobre o uso (ou não) do metilfenidato; a terceira parte contém as perguntas 4 e 5 , solicita informações sobre o número de pacientes tratados e sobre reações adversas; a quarta parte traz indagações sobre a droga e dependência química (perguntas 6 e 7); para isso, foram anexados a cada questionário os critérios diagnósticos estabelecidos pela CID-10 (ver anexo 2). Finalmente, as perguntas 8 e 9 solicitam a opinião dos médicos sobre a atual situação do controle de prescrição do metilfenidato (Notificação A).

Distribuição e coleta: Foram distribuídos 7.500 questionários, abrangendo 3.500 neurologistas e 4.000 psiquiatras do Brasil.

Os questionários foram entregues em mãos por representantes de um laboratório farmacêutico que comercializa no Brasil um produto comercial à base de metilfenidato. Os questionários foram recolhidos também pelos representantes em nova visita aos médicos, entre 30 e 45 dias mais tarde. A distribuição deste material ocorreu em fins de 2001.

Os questionários preenchidos foram em seguida encaminhados ao CEBRID e digitados para análise e interpretação dos dados.

\section{Resultados}

Foram recebidos 892 questionários preenchidos, o que corresponde a 11,9\% dos questionários distribuídos. Esse pequeno retorno já era esperado, dado ser o transtorno do déficit de atenção e hiperatividade (TDAH) uma moléstia de prevalência relativamente baixa (3\% a 6\%); devido a isso, muitos médicos informaram não atender tais pacientes e, assim, não se preocuparam em preencher o questionário. Outros informaram que não prescrevem devido à burocracia na retirada do receituário amarelo e, por essa razão, também não devolveram o questionário.

A tabela 1 mostra as quantidades de questionários distribuídos e devolvidos pelos Estados Brasileiros. Conforme pode ser visto, Espírito Santo e Goiás foram os Estados com a maior porcentagem de médicos devolvendo os questionários. Por outro lado, São Paulo, Rio de Janeiro e Minas Gerais, com 537 questionários preenchidos, foram responsáveis por $60,2 \%$ das devoluções.

Dos 892 questionários preenchidos, $411(46,1 \%)$ o foram por médicos psiquiatras, $463(51,9 \%)$ por neurologistas e $18(2,0 \%)$ por outras especialidades. Dado o pequeno número de outras especialidades, somente os questionários preenchidos pelos psiquiatras e pelos neurologistas, um total de 874 , serão considerados.

A figura 1 mostra a resposta dos médicos psiquiatras e neurologistas em relação à pergunta 1 (você prescreve o metilfenidato ...?): dos 411 (100\%) psiquiatras, $247(60,1 \%)$ responderam prescrever o medicamento, enquanto 164 (39,9\%) não; os números para os $463(100 \%)$ médicos neurologistas foram, respec- 
Tabela 1 Número de questionários sobre o metilfenidato entregues e devolvidos por psiquiatras e neurologistas do Brasil

\begin{tabular}{|c|c|c|c|}
\hline \multirow[t]{2}{*}{ Estado } & \multicolumn{2}{|c|}{ Número de questionário } & \multirow{2}{*}{$\begin{array}{l}\text { Porcentagem } \\
\text { de devolução }\end{array}$} \\
\hline & Entregues & Devolvidos & \\
\hline São Paulo & 2.760 & 141 & 5,1 \\
\hline Rio de Janeiro & 960 & 220 & 22,9 \\
\hline Minas Gerais & 860 & 176 & 20,4 \\
\hline Rio Grande do Sul & 480 & 73 & 15,2 \\
\hline Bahia & 480 & 8 & 1,7 \\
\hline Paraná & 480 & 48 & 10,0 \\
\hline Pernambuco & 360 & -- & 0,0 \\
\hline Ceará & 240 & 10 & 4,1 \\
\hline Distrito Federal & 240 & 53 & 22,1 \\
\hline Santa Catarina & 120 & 2 & 1,7 \\
\hline Goiás & 120 & 52 & 43,3 \\
\hline Espírito Santo & 120 & 78 & 65,0 \\
\hline Mato Grosso & 80 & 8 & 14,0 \\
\hline Maranhão & 70 & -- & 0,0 \\
\hline Mato Grosso do Sul & 50 & 18 & 36,0 \\
\hline Pará & 50 & 4 & 8,0 \\
\hline Alagoas & 30 & 1 & 3,3 \\
\hline
\end{tabular}

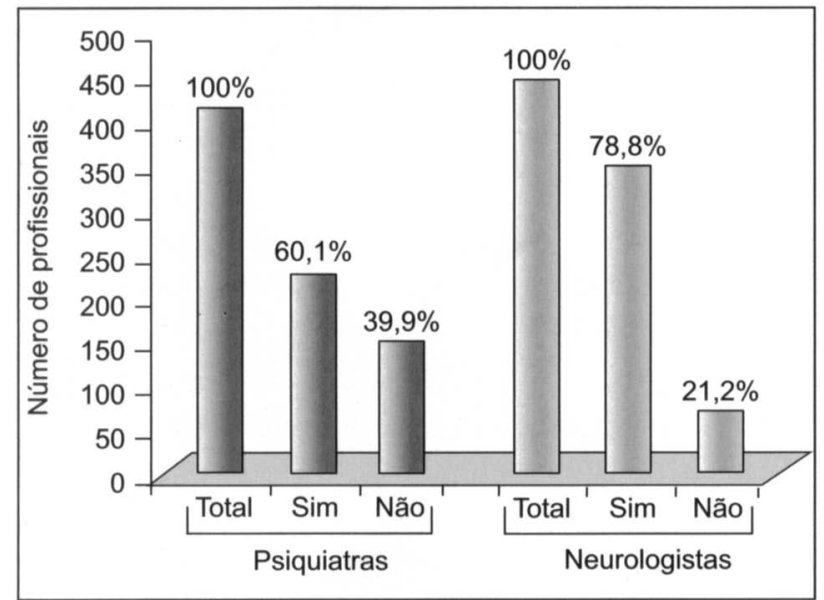

Figura 1 Profissionais médicos que prescrevem (ou não) o metilfenidato. Dos $411(100 \%)$ psiquiatras, $247(60,1 \%)$ prescrevem e $164(39,9 \%)$ não; os números para os $463(100 \%)$ neurologistas são, respectivamente, $365(78,8 \%)$ e $98(21,2 \%)$

tivamente, $365(78,8 \%)$ afirmando que prescrevem e $98(21,2 \%)$ dizendo que não.

Dos 262 médicos (164 psiquiatras e 98 neurologistas) que afirmaram não prescrever o metilfenidato no último ano, 22,9\% afirmaram não ter pacientes com o transtorno do déficit de atenção e hiperatividade (TDAH) e 17,8\% responderam utilizar outro tratamento.

Em relação ao benefício do metilfenidato no TDAH, como esperado, $99 \%$ dos médicos prescritores consideram essa terapêutica útil, havendo apenas quatro respostas em branco para este item (pergunta 3). Um quarto $(25,2 \%)$ desses médicos prescritores receitou o medicamento para mais de 10 pacientes no último ano.
Já entre os não-prescritores, $3(0,1 \%)$ dos médicos não consideram esse medicamento como importante, $120(45,6 \%)$ deixaram essa pergunta sem resposta e $140(54,3 \%)$ consideram o metilfenidato como importante no tratamento do TDAH.

A figura 2 mostra que os médicos notaram o aparecimento de reações adversas nos pacientes que receberam o metilfenidato. Assim, embora $175(28,6 \%)$ nada relatassem, os médicos restantes descreveram as seguintes reações adversas: dor de cabeça (170 médicos; 27,7\%), emagrecimento $(163 ; 26,6 \%)$, inapetência $(163 ; 26,6 \%)$, hiperexcitabilidade $(128 ; 20,6 \%)$, azia/náusea $(102$;

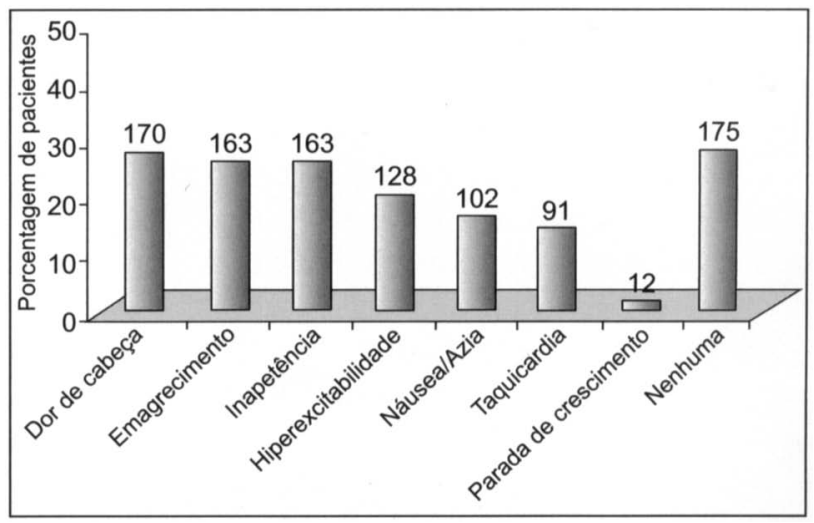

Figura 2 Porcentagem de médicos relatando reações adversas produzidas pelo metilfenidato. 175 médicos disseram não ter ocorrido reações adversas em seus pacientes (última coluna). 437 médicos relataram um total de 829 reações, sendo dor de cabeça a mais frequiente delas, citada por 170 médicos. Os números sobre as colunas indicam quantos médicos relataram a reação adversa; a soma é superior a $100 \%$, dado que, muitas vezes, um mesmo médico relatou mais de uma reação adversa 
$16,7 \%)$, taquicardia $(91 ; 14,7 \%)$, parada de crescimento $(12 ; 1,9 \%)$. Não foi descrita nenhuma reação adversa séria.

As perguntas 6 e 7 do questionário permitiram obter a opinião dos médicos, com base na própria experiência clínica, sobre a possibilidade de o metilfenidato levar pacientes a um estado de dependência. Conforme mostra a figura 3 , em relação à pergunta 6, dos 612 médicos que responderam fazer uso, $509(83,2 \%)$ disseram que o medicamento não induziu dependência em seus pacientes, mas $41(6,7 \%)$ responderam afirmativamente; houve ainda 59 respostas em branco e duas foram anuladas. A resposta restante (612a) é reproduzida na íntegra:

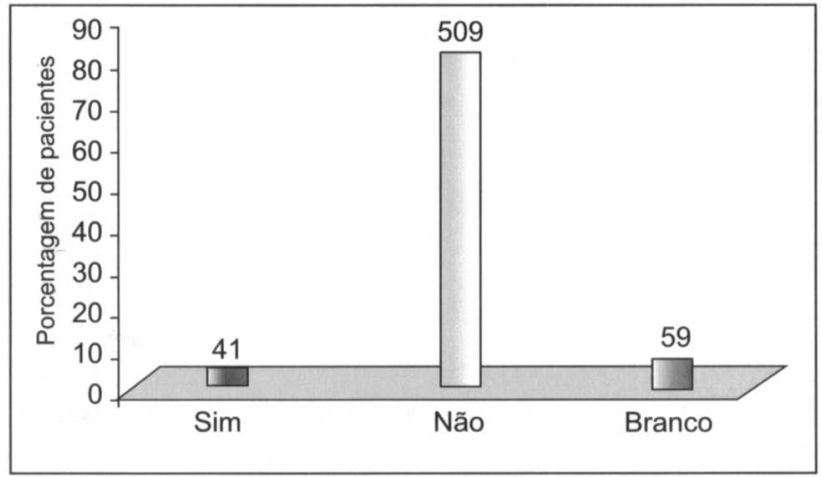

Figura 3 Opinião de 612 médicos (prescritores do metilfenidato) sobre a possibilidade de estes causar dependência. 509 (83,2\%) afirmaram não ter ocorrido dependência em seus pacientes e 41 $(6,7 \%)$ responderam positivamente a essa pergunta; desses casos apenas $6(1,0 \%)$ preenchiam, e assim mesmo parcialmente, os critérios da CID-10 para dependência. Os números acima de cada coluna indicam a quantidade de médicos que deram aquela opinião

"Em todos os doentes maiores de 12 anos, a droga apenas foi administrada pelos pais, e eu tinha total controle na prescrição desde o início até a eventual suspensão. A abstinência foi, destarte, adequadamente evitada com a retirada lenta e progressiva. Os pais foram orientados sobre o risco da falta abrupta de medicação e não a deixaram faltar".

Entretanto, ao se examinarem as 41 respostas positivas (sintomas/sinais que levaram ao diagnóstico de dependência), conforme solicitado na pergunta 7 , verificou-se que 12 médicos a deixaram sem resposta e 3 eram ilegíveis; apenas 6 respostas sugeriram, embora não preenchendo os critérios da CID-10, tratar-se de casos de dependência, conforme reproduzidas abaixo:

- "abstinência, dificuldade no desmame em um dos casos";

- "ansiedade e aumento da dose por conta própria (um caso)";

- "aumento da dosagem/busca pela substância/ tolerância";

- "piora da irritabilidade e sonolência no desmame";
- "síndrome ansiosa de retirada";

- "reação à tentativa de redução de suspensão do fármaco".

Nas restantes 20 respostas, os médicos colocaram, na realidade, os sintomas/sinais do quadro do TDAH como se fossem casos de dependência, conforme pode ser verificado em alguns exemplos abaixo:

- "agitação/déficit no aprendizado";

- "déficit de atenção/hiperatividade/baixo rendimento escolar/dificuldade de relacionamento familiar e escolar";

- “agitação, falta de limites/baixo limiar de frustração/distúrbios de sono/dificuldade na concentração e atenção";

- "pacientes com hiperexcitabilidade/desvio e transtorno de comportamento";

- "hiperatividade/déficit de atenção, só controlado com metilfenidato";

- "não termina o que começou/não pára quieto/ apresenta desinteresse por algo que acaba de se interessar".

- "pacientes que usaram como droga anorexígena".

Em síntese, dos 612 médicos que usam metilfenidato, apenas $6(1,0 \%)$ relataram casos que sugerem dependência, mas assim mesmo sem preencher os critérios da CID-10.

A figura 4 (parte A) mostra a opinião dos 612 médicos que prescrevem o metilfenidato, em relação à sua classificação na lista A3 da Portaria no 344/99 (exigência do receituário amarelo), juntamente com a anfetamina, catina, metanfetamina, etc. (Pergunta 8).

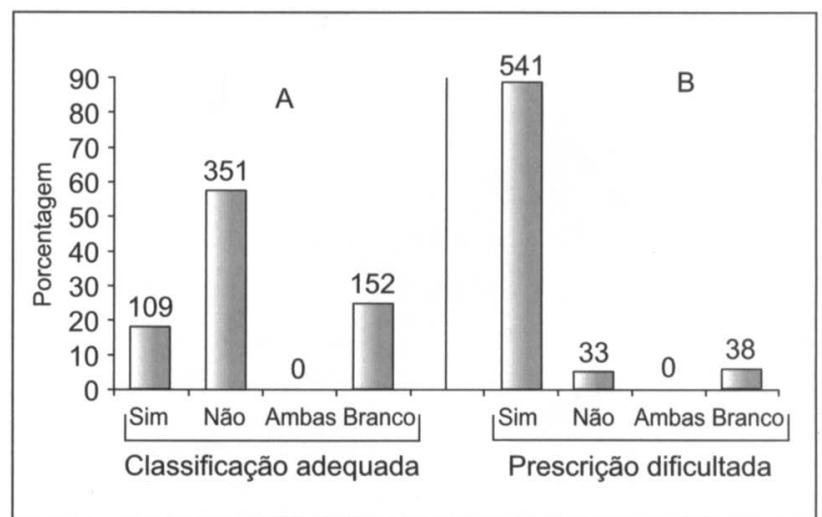

Figura 4 Opinião de 612 médicos sobre a classificação do metilfenidato na lista A3 da Portaria no 344/99 (exigência da notificação A - amarela). Na parte A os profissionais opinaram ser a atual classificação adequada ou não; na parte B deram opinião sobre a dificuldade ou não da prescrição. Os números acima de cada coluna indicam a quantidade de médicos que deram aquela opinião 
Mais da metade dos médicos $(351=57,4 \%)$ acha a classificação inadequada, $152(24,8 \%)$ deixaram a resposta em branco e apenas $109(17,8 \%)$ dos médicos opinaram ser acertada a atual classificação do metilfenidato na lista A3. A parte B da figura 4 mostra que a grande maioria dos médicos $(541=88,4 \%)$ considera que a atual classificação dificulta a prescrição do metilfenidato.

Justificando suas opiniões, os médicos que consideram a classificação inadequada apontam a dificuldade em obter o receituário amarelo A; já aqueles médicos considerando-a adequada apontam o perigo da substância em induzir dependência. Exemplos dessas opiniões estão reproduzidos abaixo. inadequada:

Exemplos de médicos que julgam a classificação

- "dificuldade de ter o formulário próprio. Como é substância prescrita dentro de especialidade médica bem definida, acredito ser suficiente o receituário já diferenciado, o azul";

- "o receituário azul controlaria adequadamente o risco de dependência, assim como de outros psicofármacos com igual potencial de abuso";

- "para facilitar a prescrição e minimizar a dificuldade dos pacientes, o ideal seria que essa substância pudesse ser prescrita no receituário $\mathrm{B}$, bem mais comum, acessível e mais prático para os psiquiatras";

- "creio que o receituário azul facilitaria a aquisição do medicamento para a família e também o tratamento";

- "as substâncias na lista B também têm controle rígido e menos burocrático";

- "o metilfenidato é uma droga muito segura e eficaz, devendo passar a ser prescrita em receituário azul";

- "as substâncias anfetaminóides vendidas como inibidoras do apetite são mais perigosas (no que tange à dependência) e são de receituário $B$. O metilfenidato é mais seguro e, quando bem indicado, não deflagra dependência nem abuso";

- "o metilfenidato não possui características de risco como as anfetaminas e, em especial, as metanfetaminas. O receituário B no meu entender teria o rigor necessário para tal controle";

- "o baixo potencial de abuso (comprovado pela literatura) não justifica tal classificação; aliado ao despreparo dos atendentes de farmácias, gera grande desconforto nos pacientes e familiares";
- "não vejo qualquer motivo para o sistema de inclusão do metilfenidato na Portaria no 344/ 99 A3. Na minha opinião, quando bem indicada, a droga é segura e eficaz";

- "cigarro e bebida alcoólica não precisam de receita";

- "o enquadramento do metilfenidato na Portaria no 344/99 é extremamente inadequado. É resultado de uma vigilância sem sentido. Quem prescreve tal medicamento pode controlar o desenvolvimento indesejado de seu uso muito melhor do que tal Portaria, sem falar no preconceito";

- "há uma contradição: inibidores de apetite em receituário $\mathrm{B}$ e metilfenidato em receituário amarelo";

- "creio tratar-se de medicação útil para o tratamento de situações clínicas específicas, e não vejo necessidade de classificá-la como substância mais perigosa do que os sedativos e os antidepressivos. Se usada com controle e com critérios, é uma droga bastante segura";

- "é medicação consagrada na literatura médica, porém pouco utilizada pela restrição no receituário amarelo, ainda em companhia das anfetaminas, que deveriam ser proibidas";

- “é um dos absurdos do nosso país que o controle do metilfenidato seja mais rígido que o das anfetaminas, como fenproporex, dietilpropiona e outras, que causam dependência e têm efeitos graves";

- "a literatura disponível indica que o metilfenidato, utilizado no tratamento de déficit de atenção com hiperatividade, não induz quadro de abuso e/ou dependência. Portanto, classificá-lo na lista A3 me parece algo bastante inadequado";

- "os estudos conduzidos com rigor metodológico não justificam que a substância seja controlada por Portaria específica (A3), e mesmo a questão da dependência no portador de TDAH não está demonstrada";

- "muitas vezes tive de desistir da prescrição, em algumas ocasiões tal a dificuldade que se encontra para a aquisição da medicação";

- "o medicamento não tem grandes efeitos colaterais, é bem administrável e seguro; assim, a receita amarela representa uma dificuldade para o médico e para o paciente, que enfrenta freqüentes transtornos para pegá-lo". 
Exemplos de médicos que julgam a classificação como adequada:

- "claro que deveria ser controlada a prescrição, porém, não como é hoje em dia";

- "julgo necessário um controle extra devido ao risco de mau uso da medicação. Porém, a dificuldade em se obter o receituário apropriado obriga-nos a optar por outras formas de tratamento, muitas vezes menos apropriadas";

- "deve existir o controle, mas precisa haver uma maneira mais rápida de médico e paciente terem acesso ao receituário amarelo";

- "embora dificulte a prescrição, creio que deva continuar dificultando mesmo, porque, embora meus portadores de TDAH não abusem do metilfenidato, não é incomum o relato por portadores de tremores relacionados à substância";

- "é interessante que se mantenha assim, pois vincula a responsabilidade à prescrição e um uso mais seguro. Mais liberdade pode aumentar o consumo pelo aumento da prescrição sem responsabilidade (vide benzodiazepínicos e a própria anfetamina)";

- "a classificação é adequada, no entanto, o receituário dificulta a prescrição";

- "tenho receio de a medicação ser liberada para prescrição de qualquer especialidade, sendo usada sem critério, como hoje ocorre com os derivados de anfetaminas nas fórmulas de emagrecer";

- "considero que deva haver controle, principalmente para que não haja abuso e uso indevido da medicação, principalmente porque tem sido comum o diagnóstico precipitado e errôneo de que todas as crianças um pouco agitadas têm hiperatividade e déficit de atenção";

- "o Brasil tem cultura para automedicação; dessa forma, entendo que os psicotrópicos têm que ser usados com critérios, e, se houver necessidade da medicação acima citada, não vejo transtorno para solicitação de receituário especial à SN";

- "é necessário evidentemente o controle adequado, porém, a questão do receituário dificulta a prescrição, em especial no serviço público".

Há ainda a ressaltar que literalmente centenas de médicos queixaram-se dos entraves burocráticos para obtenção do receituário $\mathrm{A}$, em contraste com apenas 4 dos médicos que declararam não ter problemas em obter o mesmo receituário:

- "não há problemas em buscar o receituário";

- "consigo buscar o receituário sempre que preciso";

- "não vejo qualquer dificuldade; é só ter disposição para buscar".

Finalmente, a figura 5 traz a opinião dos médicos prescritores, respondendo à pergunta 9 do questionário, relativa à exigência de notificação A e suas conseqüências sobre os pacientes, seus familiares e os próprios médicos.

Em relação à possibilidade de "amedrontar", 444 $(72,5 \%)$ dos médicos responderam que a notificação A realmente preocupa os pacientes e, principalmente, os familiares, pois em geral os pais acabam por desconfiar se a doença é mais séria do que lhes está sendo dito, pois, caso contrário, não seria tratada com remédio "tão controlado"; ou que esse pode causar mal aos doentes, dado ser remédio perigoso.

A maioria dos prescritores, 532 (86,9\%), também menciona que as exigências requeridas pela notificação A acabam por tornar o metilfenidato pouco disponível, dado o desinteresse das farmácias em manter em estoque produto que exige excesso de burocracia. Alguns relataram casos de parentes que se locomovem até outras cidades para obter o medicamento.

É relevante ainda que quase $70 \%$ dos médicos (424) relatam que a apresentação da notificação A é muitas vezes constrangedora para os pais, pois o balconista da farmácia ou outras pessoas os olham de maneira "diferente". Como se tivessem "comprando remédio de viciado".

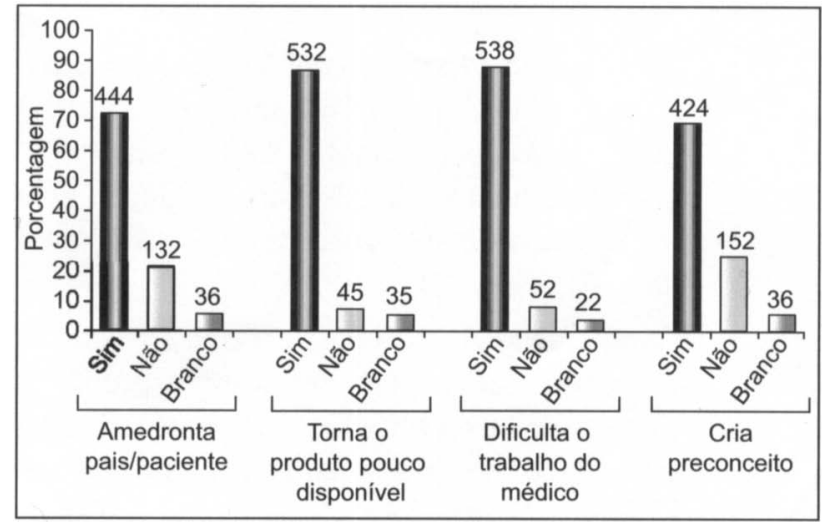

Figura 5 Opinião de 612 médicos sobre a exigência da notificação A para a prescrição do metilfenidato. A grande maioria dos médicos respondeu que a exigência amedronta os pais/doentes (444 médicos), torna o produto pouco disponível (532), dificulta o trabalho do médico (538) e cria preconceito sobre o TDAH (424). 
Diante desses aspectos negativos, não causa espécie o fato de 538 dos médicos respondentes $(87,9 \%)$ afirmarem que a notificação A para o metilfenidato dificulta o trabalho médico.

\section{Discussão}

Um total de 47 substâncias já foram ou são utilizadas no tratamento do TDAH (Jadad et al., 1999), entre essas destacando-se o uso de estimulantes do sistema nervoso central, como anfetaminas (Patrick e Markowitz, 1997; Manos et al., 1999), pemolina (Patrick e Markowitz, 1997; Andriola, 2000) e cafeína (Spencer et al., 1996); além desses, antidepressivos, como imipramina, bupropiona, fluoxetina e substâncias várias, como clonidina, etc. são também utilizados (Rohde et al., 2000).

Entretanto, parece não haver dúvidas de que a preferência dos médicos para o tratamento recai sobre o metilfenidato (Spencer et al., 1996; Greenhill et al., 1999; Miller et al., 2001). De fato, cerca de 150 trabalhos científicos já publicados sobre o uso de psicoestimulantes, principalmente do metilfenidato, atestam a sua boa eficácia e a baixa toxicidade (Barkley et al., 1990; Jadad et al., 1999; NIH - MTACooperative Group, 1999; Rohde et al., 2000; Gilmore e Milne, 2001).

Um dado adicional importante, que se soma aos benefícios diretos do metilfenidato no TDAH, consiste no seu efeito "antidependência". De fato, sabe-se que as crianças sofrendo de TDAH têm muito maior probabilidade de tornarem-se dependentes de outras drogas quando adultos; porém, quando tratadas com o metilfenidato, esse risco futuro diminui significativamente em até $85 \%$ (Biederman et al., 1999).

Neste estudo, o índice de preenchimento e entrega dos questionários enviados foi muito baixo: 7.500 distribuídos/892 devolvidos devidamente preenchidos, o que corresponde a $11,9 \%$ de respostas. Isso poderia levar a um resultado com vies; por exemplo, só teriam respondido aqueles médicos de alguma maneira entusiastas do medicamento. Entretanto, isso é pouco provável pelas seguintes razões:

- também é igualmente possível que tenham respondido aqueles médicos mais interessados em aspectos de pesquisa em medicina, e assim fizeram com genuína contribuição parcial;

- o índice de respostas para questionários, em levantamentos epidemiológicos, é reconhecidamente muito baixo (Bauman e Phongsavan, 1999);
- em nosso meio médico, essa abstenção (desinteresse?) por parte dos médicos é particularmente gritante; em outro levantamento epidemiológico feito por nós (Carlini et al., manuscrito em preparação), o índice de resposta foi também muito baixo;

- finalmente, e mais importante, o TDAH é entidade de prevalência pequena na população e ainda pouco reconhecido e tratado; por essas razões, muitos médicos informaram não tratar pacientes com TDAH e simplesmente não devolveram o questionário.

No presente trabalho, em relação às reações adversas, $15 \%$ a $30 \%$ dos médicos respondentes (Figura 4) relataram o aparecimento em seus pacientes de reações adversas não sérias, como dor de cabeça, perda de peso, inapetência e hiperexcitabilidade. Esses achados estão em acordo com relatos internacionais mostrando que cerca de $70 \%$ dos pacientes toleram bem o medicamento (Spencer et al., 1996; Schachter et al., 2001).

Por outro lado, o sistema de psicofarmacovigilância do CEBRID (PSIFAVI) já recebeu mais de 200 notificações de reações adversas enviadas por psiquiatras, produzidas por medicamentos psicoativos, e em nenhuma dessas o metilfenidato foi apontado como suspeito. Ainda, segundo informações do laboratório que comercializa o único produto à base de metilfenidato no Brasil, de janeiro de 1998 a julho de 2001 não foram relatados casos de dependência e apenas sete casos de eventos adversos, nenhum deles sérios; nesse período o consumo brasileiro foi superior a 8,5 milhões de comprimidos, correspondendo a 15.571 pacientes. No mês de julho de 2001, calculou-se que 7.413 pacientes estavam em uso do medicamento.

$\mathrm{O}$ pequeno número de pacientes brasileiros que recebem o metilfenidato merece maiores reflexões. A prevalência do TDAH em crianças e adolescentes está estimada em 3\% a 6\% (Goldman et al., 1998; Schachter et al., 2001; Brown et al., 2001), embora valores tão altos, como $26 \%$, tenham também sido relatados (Newcorn et al., 1994). No Brasil a prevalência da síndrome está avaliada entre 3\% a 6\% (Rohde et al., 1998 ; 2000). Por outro lado, a população brasileira entre 12 e 17 anos está calculada em aproximadamente 28 milhões (IBGE, Censo 2000). Portanto, o número de crianças e adolescentes, com idade entre 12 e 17 anos com o TDAH, deveria oscilar entre 840.000 e 1.680 .000 de pacientes.

Depreende-se daí que o número de 7.413 pacientes que recebem o metilfenidato em julho de 2001 é extremamente pequeno em relação ao universo brasileiro com o 
transtorno de déficit de atenção e hiperatividade, considerando ser o metilfenidato o tratamento de eleição para esse transtorno.

Entre várias possíveis razões que poderiam explicar tão baixo número de eventuais pacientes, desponta a exigência da notificação A (amarela) para a prescrição de metilfenidato. De fato, de acordo com as figuras 4 e 5 , a imensa maioria dos médicos prescritores considera que a exigência da notificação A é inadequada, dificulta a prescrição, amedronta os pais dos pacientes, torna o produto pouco disponível e cria preconceitos sobre a terapêutica.

Por outro lado, embora os médicos brasileiros não considerem o metilfenidato como um forte indutor de dependência, a literatura mundial aponta tais casos como abuso (para revisão, ver Kollins et al., 2001). Mas, seguramente, o metilfenidato não possui o mesmo perfil farmacotoxicológico das outras substâncias classificadas na lista A3, tais como anfetamina (dexanfetamina), catina, dronabinol (outro nome do D9 tetra-hidrocanabinol, princípio alucinógeno da Cannabis sativa), metanfetamina ("ice"), fenciclidina ("pó de anjo"), etc.
Pareceria, portanto, pertinente, de acordo com a sugestão dos médicos, que o metilfenidato fosse reenquadrado na lista B1 (exigindo a notificação B, azul) de substâncias psicotrópicas, que inclui barbitúricos, benzodiazepínicos, pemolina, etc. As substâncias da lista B1 também são consideradas indutoras de dependência e suas embalagens levam faixa preta com advertência sobre a indução de dependência. Mas, diferentemente dos opiáceos (morfina, meperidina, oxicodona, ópio, etc.), que também necessitam da Notificação A, as substâncias da lista B1 exigem a Notificação B, com menor exigência de controle, bem de acordo com a muito menor toxicidade do metilfenidato.

Esta decisão, caso tomada, viria atender à solicitação das Nações Unidas, ao analisar as consequiências das medidas de segurança para evitar o tráfico sobre a disponibilidade de certos medicamentos, no caso, os narcóticos, mas que bem poderia ser mencionada também para o metilfenidato:

"O controle de drogas, por si próprio indispensável para prevenir o abuso, não deveria de nenhuma maneira privar os pacientes dessas drogas, por diminuir suas disponibilidades"- E/INCB/C.L.355, abril 1995.

\section{Anexo 1. Questionário sobre efeitos adversos do metilfenidato*}

*Nota - O único produto comercial existente no Brasil à base de metilfenidato é conhecido pelo nome de Ritalina ${ }^{\circledR}$

I) Identificação do médico

Nome

\begin{tabular}{lr} 
Especialidade & CRM \\
Cidade & Estado \\
Endereço & \\
Telefone & \\
\hline
\end{tabular}

II) Sobre o uso do metilfenidato

1. Você prescreve o metilfenidato para o tratamento da síndrome do transtorno de déficit de atenção e hiperatividade (TDAH)?
$\square \operatorname{sim}$
$\square$ não

2. No caso de resposta negativa à pergunta 1:

Não tenho pacientes com esta síndrome

Utilizo outro tratamento para a síndrome

3. Na sua opinião o uso do metilfenidato traz benefícios para o tratamento de TDAH?

$\square \operatorname{sim} \square$ não 
III) Sobre as reações adversas produzidas pelo metilfenidato:

(Em caso de resposta positiva à pergunta 1)

4. Nos últimos 12 meses para quantos pacientes você prescreveu o metilfenidato:

$\begin{array}{ll}\square \text { nenhum } & \square \text { 1 a } 3 \\ \square \text { 4 a } 7 & \square \text { 8 a } 10 \\ \square \text { mais de } 10 & \square \text { especificar }\end{array}$

5. No caso de ter prescrito o metilfenidato nos últimos 12 meses, você notou o aparecimento de alguma(s) das reações adversas descritas abaixo em algum(s) paciente(s)? Se sim, quantos casos?

Emagrecimento

\begin{tabular}{|c|c|c|}
\hline $\operatorname{sim}$ & não & casos (quantidade) \\
\hline $\operatorname{sim}$ & não & _ casos (quantidade) \\
\hline $\operatorname{sim}$ & não & casos (quantidade) \\
\hline $\operatorname{sim}$ & não & casos (quantidade) \\
\hline $\operatorname{sim}$ & não & _ casos (quantidade) \\
\hline $\operatorname{sim}$ & não & casos (quantidade) \\
\hline $\operatorname{sim}$ & não & __ casos (quantidade) \\
\hline
\end{tabular}

IV) O metilfenidato e dependência química:

6. Ao longo de sua experiência clínica com o metilfenidato, você observou pacientes que preenchiam os critérios diagnósticos (ver critérios CID-10 anexo) para serem considerados como dependentes?
$\operatorname{sim}$ não

7. No caso de resposta positiva à pergunta 6 , quais foram os sinais/sintomas que levaram ao diagnóstico positivo?

Nas perguntas 8 e 9 poderá ser assinalada mais de

uma resposta, caso seja necessário e relevante para o ideal desenvolvimento de seu trabalho.

8. De acordo com a Portaria no 344/99, o metilfenidato está classificado na lista A3 (lista de substâncias psicotrópicas), juntamente com anfetamina, catina e metanfetamina ("ice"), todas substâncias de uso proibido no Brasil. Na sua opinião, tal classificação:

É adequada $\square$ sim $\square$ não

Dificulta prescrição $\square$ sim $\square$ não

Obs.: Qualquer que seja sua opinião, justificar brevemente:

9. Pelo fato de estar na lista A3 da Portaria no 344/99, a prescrição do metilfenidato deve ser feita com a notificação da receita A (cor amarela), como é também o caso da morfina (classificada na lista A1 da Portaria no 344/99). Na sua opinião essa exigência:

$\begin{array}{ll}\text { Amedronta o paciente (ou familiares) } & \square \operatorname{sim} \quad \square \text { não } \\ \text { Torna o produto pouco disponível na farmácia } & \square \operatorname{sim} \quad \square \text { não } \\ \begin{array}{l}\text { Dificulta o seu trabalho } \\ \text { (por exemplo, obtenção do bloco de receituário) }\end{array} & \square \operatorname{sim} \quad \square \text { não } \\ \begin{array}{l}\text { Cria um preconceito em relação à condição } \\ \text { do paciente }\end{array} & \square \operatorname{sim} \quad \square \text { não }\end{array}$




\section{Anexo 2. Síndrome de dependência (CID-10)}

Um conjunto de fenômenos fisiológicos, comportamentais e cognitivos, no qual o uso de uma substância ou uma classe de substâncias alcança uma prioridade muito maior para um determinado indivíduo do que outros comportamentos que antes tinham maior valor. Uma característica descritiva central da síndrome de dependência é o desejo (freqüentemente forte, algumas vezes irresistível) de consumir drogas psicoativas (as quais podem ou não ter sido medicamente prescritas), álcool ou tabaco. Pode haver evidência de que o retorno ao uso da substância após um período de abstinência leve a um reaparecimento mais rápido de outros aspectos da síndrome do que o que ocorre com indivíduos não-dependentes.

\section{Diretrizes diagnósticas}

Um diagnóstico definitivo de dependência deve usualmente ser feito somente se três ou mais dos seguintes requisitos tenham sido experenciados ou exibidos em algum momento durante o ano anterior:

(a) um forte desejo ou senso de compulsão para consumir a substância;

(b) dificuldades em controlar o comportamento de consumir a substância em termos de seu início, término ou níveis de consumo;

(c) um estado de abstinência fisiológico quando o uso da substância cessou ou foi reduzido, como evidenciado por: a síndrome de abstinência característica para a substância ou o uso da mesma substância (ou de uma intimamente relacionada) com a intenção de aliviar ou evitar sintomas de abstinência;

(d) evidência de tolerância, de tal forma que doses crescentes da substância psicoativa são requeridas para alcançar efeitos originalmente produzidos por doses mais baixas (exemplos claros disso são encontrados em indivíduos dependentes de álcool e opiáceos, que podem tomar doses diárias suficientes para incapacitar ou matar usuários não tolerantes);

(e) abandono progressivo de prazeres ou interesses alternativos em favor do uso da substância psicoativa, aumento da quantidade de tempo necessário para obter ou tomar a substância ou para se recuperar de seus efeitos;

(f) persistência no uso da substância, a despeito de evidência clara de conseqüências manifestamente nocivas, tais como dano ao fígado por consumo excessivo de bebidas alcoólicas, estados de humor depressivos consequientes a períodos de consumo excessivo da substância ou comprometimento do funcionamento cognitivo relacionado à droga; deve-se fazer esforços para determinar se o usuário estava realmente (ou se poderia esperar que estivesse) consciente da natureza e da extensão do dano.

\section{Referências bibliográficas}

ANDRIOLA, M.R. - Efficacy and Safety of Methylphenidate and Pemoline in Children with Attention-Deficit Hyperactivity disorder. Current Therapeutic Research 61: 208-15, 2000.

Barkley, R.A.; McMurRay M.B.; Edelbrock C.S. et al. - Side Effects of Methylphenidate in Children with Attention-Deficit Hyperactivity Disorder: A Systemic, Placebo-Controlled Evaluation. Pediatrics 86: 184-92, 1990.

Bauman, A.; Phongsavan P. - Epidemiology of Substance Use in Adolescence Prevalence, Trends and Policy Implications. Drug and Alcohol Dependence 55: 187-207, 1999.

Biederman, J.; Wilens, T.; Mick, E. et al. - Pharmacotherapy of Attention-Deficit/Hyperactivity Disorder Reduces Risk For Substance Use Disorder. Pediatrics 104: 20-5, 1999.

Brown, R.T.; Freeman W.S.; Perrin J.M. et al. - Prevalence and Assessment of Attention-Deficit/Hyperactivity Disorder in Primary Care Settings. Pediatrics 107: 43-54, 2001.

Claudio, B. - Informações Não-Publicadas Sobre o Metilfenidato (Ritalina $\left.{ }^{\circledR}\right)$, setembro 1991.

Gilmore, A.; Milne, R. - Methylphenidate in Children with Hyperactivity: Review and Cost-Utility Analysis. Pharmacoepidemiology and Drug Safety 10: 85-94, 2001.

Goldman, L.S.; Genel, M.; Bezman R.J. et al. Diagnosis and Treatment of Attention-Difficulty/Hyperactivity Disorder in Children and Adolescents. JAMA 279: 1100-7, 1998.

Greenhill, L.L.; Halperin, J.M.; AвIKofF, H. - Stimulant Medications. Journal of American Academy of Child and Adolescent Psychiatry 38: 503-12, 1999.

JADAD, A.R.; Boоker, L.; GAuld, M. et al. - The Treatment of Attention-Deficit/Hyperactivity Disorder: An Annotaded Bibliography and Clinical Appraisal of Published Systematic Reviews and Meta-Analyses. Canadian Journal of Psychiatry 44: 1025-34, 1999.
Kollins, S.H.; MacDonald, E.K.; Rush, C.R. - Assessing the Abuse Potential of Methylphenidate in Nonhuman and Human Subjects. Pharmacology, Biochemistry and Behavior 68: 611-27, 2001.

Manos, M.J.; Short, E.J.; FindLING, R.L. - Differential Effectiveness of Methylphenidate and Adderall ${ }^{\circledast}$ in School-Age Youths with Attention-Deficit/Hyperactivity Disorder. Journal of American Academy of Child and Adolescent Psychiatry 38: 813-9, 1999.

Miller, A.R.; Lalonde, C.E.; McGrail, K. et al. - Prescription of Methylphenidate to Children and Youth, 1990-1996. Canadian Medical Association Journal 165: 1489-94, 2001.

Newcorn, J.M.; Halperin, J.M.; Schwartz, S. et al. - Parent and Teacher Ratings of Attention-Deficit/Hyperactivity Disorder Symptoms: Implications for Case Identifications. Journal of Developmental and Behavioral Pediatrics 15: 86-91, 1994.

NIH-MTA CoOperative Group. - A 14-Month Randomized Clinical Trial of Treatment Strategies for Attention-Deficit/Hyperactivity Disorder. Archives of General Psychiatry 56: 1073-86, 1999.

Patrick, K.S.; Markowitz, J.S. - Pharmacology of Methylphenidate, Amphetamine Enantiomers and Pemoline in AttentionDeficit/Hyperactivity Disorder. Human Psychopharmacology 12: 527-46, 1997.

Rohde, L.A.; Busnello, E.A.; Chachamovich, E. et al. - Transtorno de Déficit de Atenção/Hiperatividade: Revisando Conhecimentos. Revista da ABP-APAL 20: 166-78, 1998.

Rohde, L.A; Barbosa, G; Tratmontina, G et al. - Transtorno de Déficit de Atenção/Hiperatividade. Revista Brasileira de Psiquiatria 22(Supl. II): 7-11, 2000.

Schachter, H.M.; Pham, B.; King, J. et al. - How Efficacious and Safe is Short-Acting Methylphenidate for the Treatment of AttentionDeficit Disorder in Children and Adolescents? A metha-analysis. Canadian Medical Association Journal 165: 1475-88, 2001.

Spencer, T.; Biederman, J.; Wilens, T. et al. - Pharmacotherapy of Attention-Deficit/Hyperactivity Disorder Across the Life Cycle. Journal of American Academy of Child and Adolescent Psychiatry 35: 405-25, 1996. 